\title{
Is There Such a Thing as Psychological Pain? and Why It Matters
}

\author{
David Biro
}

Published online: 13 September 2010

(C) The Author(s) 2010. This article is published with open access at Springerlink.com

\begin{abstract}
Medicine regards pain as a signal of physical injury to the body despite evidence contradicting the linkage and despite the exclusion of vast numbers of sufferers who experience psychological pain. By broadening our concept of pain and making it more inclusive, we would not only better accommodate the basic science of pain but also would recognize what is already appreciated by the layperson-that pain from diverse sources, physical and psychological, share an underlying felt structure.
\end{abstract}

Keywords Physical pain · Psychological pain · Emotional pain · Nociceptor · Affective pain center $\cdot$ Grief · Depression

All pain is one malady with many names.

-Antiphanes, ca. 400 BC

\section{Introduction}

"They say passing a kidney stone is the worst pain you could ever have. They're wrong. Sure it was bad. I remember whimpering like a baby in the Emergency Room. But it was a joke compared to this pain which never passes. It just keeps on going and eating me up inside. I still feel it now, intense as ever, 10 years later." Dan Vento is talking about the time his daughter suffered a relapse of an uncommon form of cancer called osteosarcoma. Jennifer was nine, the youngest of his three daughters. Dan and his wife Mary thought they had weathered the storm. The initial round of chemotherapy seemed to work. But a year later, Jennifer's left knee began

D. Biro $(\bowtie)$

SUNY Health Science Center at Brooklyn, 450 Clarkson Avenue, Brooklyn, NY 11203, USA

e-mail: davidbiro@aol.com 
to swell and hurt again, then her thigh, then her back. The cancer not only had returned but was now all over Jennifer's body, and it had happened so quickly that even the doctors were caught off guard.

Naturally the Ventos tried everything, even a bone marrow transplant. But the cancer could not be stopped. Metastatic tumors invaded Jennifer's bones, obstructed her airways and destroyed her vision. Overnight, their little girl had become unrecognizable, from the cancer and from the aggressive treatments-a swollen, lumpy mass with tubes and IV lines hooked up to beeping machines. The worse part was that there was nothing they could do to help. They stood by, feeling as if the cancer were ripping through their bones too.

Less than 2 months after the relapse Jennifer died. It was almost a relief at first; the Ventos couldn't bear watching their daughter suffer another day. But when they saw Jennifer in the little coffin, when they saw the coffin lowered into the ground, when they saw the earth covering the coffin-from that day on, their pain would never end.

"I tried to be strong for my wife and kids," Dan Vento explained. "If they saw me crumble, how would they be able to keep going?" But despite the strong facade, Vento was crumbling. "I felt weak and lightheaded all the time, like I might pass out, and needed to grab onto something — a chair, the wall, anything - to keep from falling."

Vento had always been tough. Though not physically imposing-he was short and stocky - he was a self-made man from the Bronx who owned a successful chain of grocery stores and always got whatever he wanted, at work and at home. When Jennifer died, however, he didn't seem to want much anymore and found it increasingly difficult to concentrate. His life began to unravel. There was only pain.

\section{Diverging Views}

Is what Dan Vento experienced-as he watched his daughter suffer, when he buried her, and now, 10 years later, still entangled in grief-pain? He certainly thinks so and uses the word just as he did when he spent an agonizing night in the ER with kidney stones. So do many other people who undergo similar trauma, as well as those who suffer "pain" in psychiatric illnesses like depression and schizophrenia.

Most professionals, however, would disagree. Scientists who study pain and doctors who treat pain consider the experience a strictly physical phenomenon, in the sense that it can only be caused by injury to the body. Pain occurs when receptors on nerve cells in the skin and internal organs detect potentially damaging stimuli, a pinrick, for example, or high temperatures (Melzack and Wall 1983, pp. 81-108). The nociceptors (from the Latin nocere, to injure) then signal the brain, which assesses the threat and coordinates a series of protective responses. We pull the arm away from the flame; we rest the broken leg. This highly effective biological warning system that prevents further damage and aids in healing is something we can't live very well without. Just think of patients who are unable to feel pain, those with genetic defects and those with diseases that affect nerve transmission like diabetes and leprosy; the benefits of life without pain are easily outweighed by the negatives of progressive injury to the body and premature death (see Brand and Yancey 1997). 
Dan Vento has suffered no physical injury. Nor have patients who experience the psychic pain that accompanies acute depression. Nor have cancer patients (and their parents) who experience the overwhelming fear and anxiety and isolation that accompany the physical symptoms of their illnesses. Their nociceptors, at least with respect to these particular feelings, remain silent, sending no distress signal to the brain. Therefore, their feelings are not really pain but something categorically different, what the professionals prefer to call suffering or anguish (Cassell 1991, pp. 30-46). And therefore, one will find no mention of grief or depression in medical classification schemes of pain.

Even psychiatrists are wary of speaking about pain in their patients, reserving it only for those rare and strange cases of psychogenic pain or somatoform pain disorder - that is, physical-like pain localized to a part of the body that has not been injured, the modern-day equivalent to what Freud termed hysteria or conversion reaction (DSM 3, rev.; American Psychiatric Association 1987). The bottom line is that the psychological pain experienced by Dan Vento and millions of patients with acute depression is an oxymoron or, at best, a metaphor. It simply does not exist. ${ }^{1}$

\section{The Subjective Argument}

How can there be such a gulf between the layperson and the expert, especially with regard to such a common part of life? And if the experts are right, how could ordinary people like Dan Vento as well as our language professionals-celebrated writers like William Styron and Joan Didion, for example, who wrote so eloquently about pain in depression (Darkness Visible) and grief (The Year of Magical Thinking)— have gotten things so wrong?

Unless of course they haven't. Unless it's not the layperson but the expert who is confused. Perhaps one's instinctive tendency to see pain more broadly, as a category that incorporates both physical and psychological varieties, may be more enlightened than the expert's narrower conception. Perhaps there are good reasons for speaking of pain in the setting of grief or depression or schizophrenia or divorce or the nonphysical suffering that accompanies illness.

Let's examine the evidence. In the first place, there is a wealth of subjective evidence-what people feel and think and then convey to others through language. When we ask people about certain aversive emotional experiences and listen to their words, we find that they not only use the generic word "pain" to label these experiences, but also describe them in the same ways they describe physical pain. Now pain of any kind is notoriously difficult to express. There are problems conceptualizing the experience because it is perceptually inaccessible (we can't see or touch pain) and because, unlike other inner states, it is not always linked to external objects that we can see or touch (like the person who makes us angry or the

\footnotetext{
${ }^{1}$ I am arguing here neither that psychic distress is any less real than physical pain nor that somatic complaints can accompany psychiatric illness-in fact, $50 \%$ of depressed patients report symptoms of physical pain (Katona et al. 2005) - but that psychic distress can itself be painful in a meaningful sense, that it can be phenomenologically akin to physical pain and, therefore, should be categorized under the same rubric.
} 
dog that makes us scared) (Scarry 1985, pp. 161-162; Biro 2010, pp. 11-47). As a result, one is forced to think about pain indirectly, through metaphor: we imagine a more knowable object linked to the pain and then speak of the experience in terms of that object.

By far the most common metaphor used to describe physical pain is the weapon (Scarry 1985, pp. 15-19). We say that a pain is shooting or stabbing. Lengthy lists of similar adjectives can be found on the McGill Pain Questionnaire, created in the 1970s to help patients communicate their feelings to doctors. Pain can be described as piercing, drilling, burning, grinding, throbbing, stinging, squeezing, and so on. Each of the descriptors implies the presence of a weapon or weapon-like object that can injure the body-the drill that drills, the fire that burns. And since most patients have never been stabbed or shot or are not being stabbed or shot at the moment of pain, they are using these terms figuratively to objectify what would otherwise be difficult to pin down and represent; now they could see pain and describe how it feels by talking about knives and guns and the damage they can do the body.

People with psychological pain use the very same metaphors to describe their experiences. Dan Vento, silenced for so long by the incapacitating pain of loss, will eventually open up to a psychiatrist. It felt like a bomb, he explained, that exploded inside of him, obliterating everything in his body. At other times, he felt the damage was occurring more slowly and methodically, as if there were a swarm of parasites eating away at his organs. But either way, the result was the same for Vento: he was being emptied out from the inside- "gutted" was the word he used-until all that was left was a big, raw gaping wound.

When her husband died and she was flooded with grief, Joan Didion saw giant waves. In her memoir, she writes that she felt as if she were being battered by "destructive waves, paroxysms, sudden apprehensions that weaken the knees and blind the eyes and obliterate the dailiness of life" (Didion 2005, pp. 27-28). For Kay Redfield Jamison, a psychiatrist who suffers from manic depression, the weapon is a giant centrifuge, containing tubes of her blood. It spins around her mind faster and faster, out of control, until it explodes, splattering blood everywhere (Jamison 1996, p. 80).

Listening to the language of pain of all kinds, we discover a shared felt structure that the weapon metaphor effectively captures (Biro 2010, pp. 79-96). Whether triggered by grief and depression or kidney stones and spinal injury, pain reads like a story in three parts:

$$
\text { Weapon } \rightarrow \text { Injury } \rightarrow \text { Withdrawal. }
$$

In pain we feel as if there must be some weapon-like object (bomb, swarm of parasites, giant wave, centrifuge) that is moving toward and threatening us; that when it strikes, it will injure, possibly even destroy us; and that we must get away from it or shield ourselves at all costs. Even when there is nothing coming at us, when there is no injury, when we remain motionless, we feel the movement, the injury and the desire to run.

Whatever happens that makes us feel these things - the loss of a loved one or the physical destruction of cancer-we experience pain. 


\section{New Objective Evidence}

The subjective evidence for the existence of emotional pain is compelling, especially since there is no objective way to verify and characterize someone else's pain. Although we can attach a person to a functional magnetic resonance imaging (fMRI) device, observe the blood flow to pain centers in the brain and then infer its presence, the only definitive test is a person's word: I feel pain or I don't.

Actually, most experts grudgingly acknowledge the inescapably subjective nature of pain. In an addendum to their universally accepted definition of pain- "An unpleasant sensory and emotional experience associated with actual or potential tissue damage" - the International Association for the Study of Pain (IASP 2007) concedes that people do report pain for strictly psychological reasons and that, since such reports can't be distinguished from instances where there is a physical cause, they should be taken at face value: "If people regard their experience as pain and if they report it in the same ways as pain caused by tissue damage, it should be accepted as pain."

But despite the concession, the IASP does not make room for the pain experienced by Dan Vento, Joan Didion, or Kay Redfield Jamison on their extensive classification schemes of pain disorders. While complex regional pain-which affects somewhere of the order of 6-26 people in 100,000 (de Mos et al. 2007) appears on the list, the vastly more common pain occurring in grief or depression does not.

For physicians and scientists that will only pay lip service to the subjective argument, however, there is now mounting objective evidence for broadening our notion of pain. Since the introduction of gate control theory in the 1960s, the link between tissue damage and pain has progressively weakened. We now have a better understanding why there can be severe injury and no pain (wounded soldiers in battle) and, conversely, no injury and severe pain (migraine, fibromyalgia). This happens, as prominent pain scientists Ronald Melzack and Patrick Wall have explained, because there are psychological factors-one's culture and past experiences, our emotional and cognitive states, the context of pain-that can intensify or dampen the nociceptor signal before it registers in higher brain centers (Melzack and Wall 1983, pp. 15-33). Moreover, many cases of chronic pain seem to occur without any direct nociceptor stimulation at all. Neuropathic pain results when a dysfunctional nervous system fires spontaneously or misinterprets ordinary sensory stimuli as noxious (Woolf and Mannion 1998). In tic dolouroux, for example, the movement of a feather across the face can trigger spasms of intense pain.

A second strand of evidence comes from our growing understanding of how the brain processes pain. It turns out that pain is an incredibly complex perceptual system with multiple subsystems. Most important for this discussion, there are distinct areas in the brain that process the sensation of pain (its quality, location, intensity) and our feelings about the sensation (the narrative of its aversiveness) (Price 2000). Further, the sensory center (in the somatosensory cortex) and the affective center (in the anterior cingulate and insula cortices) are not only spatially apart but dissociable: that is, a person can have the sensation of 
pain but not feel pain (Grahek 2007, pp. 29-50). We can observe this in patients undergoing minor surgery with medication that makes them indifferent to being cut with a scalpel. Even more dramatic is a rare group of patients whose affective pain centers (or the connections to those centers) have been destroyed. In the case of pain asymbolia, patients can still sense a needle prick (because the nociceptor signal registers in the somatosensory cortex) but will laugh at its insignificance (because the signal is not processed by the anterior cingulate cortex).

These instances of disconnect between the sensation and the feeling of pain tell us that despite the complexity of pain-which involves sensations and behavior, feeling, cognition and memory-the critical component is feeling. If we don't have the feelings that Dan Vento had when the kidney stone was passing through his ureter-that something bad was happening to him, that that something was damaging his body, and that he must do whatever he could to avoid further damage - then pain loses its biological value. Because they laugh at pain rather than run from it, pain asymbolia patients will likely fare no better than patients with congenital or acquired pain insensitivity. In fact, I would argue that if we don't feel pain, there's no point using the term at all. Leprosy patients, soldiers on the battlefield, sedated patients undergoing surgery, pain asymbolia patients-they may experience unpleasant sensations but they don't feel pain and don't take protective measures. Everything is contingent on the feeling of pain.

If tissue damage is not necessary to feeling pain and if there is a special affective center in the brain devoted to such feeling, why can't that center be activated by means other than the nociceptor pathway? Why isn't it possible that noxious psychological stimuli-stimuli that threaten the emotional well-being of a person, like the loss of a child or the pain of depression or the suffering of cancer patientsfind their way to the anterior cingulate gyrus, making us feel the same way we do when we experience physical pain?

This is precisely what scientists are discovering. Naomi Eisenberger and her colleagues at UCLA have recently developed a clever model of psychological pain that can be studied objectively (Eisenberger et al. 2003). Normal subjects played a video ball-tossing game while their brains were monitored by fMRI. When the subjects were excluded from the virtual game, they experienced distress that correlated with increased blood flow to the anterior cingular and insular cortices, exactly the same pattern that would have occurred had they been stuck by a needle. The greater the social distress generated, the more active these affective pain centers became. Studies done on saddened and grieving subjects produced similar results (Gundel et al. 2003).

It appears that the layperson's intuition about pain is being borne out by science; psychological pain seems to run on the same neural tracks as physical pain. And why shouldn't it? Just as physical stimuli that can damage our bodies prompt certain feelings and responses, so too should psychological stimuli that can damage our psyche like the loss of a child or the intrinsic symptoms of depression. Just as we need to rest the body to protect ourselves from further harm, so too should we protect the mind. This more complete and comprehensive warning system certainly makes sense from a biological perspective. 


\section{Why Words Matter}

Does it matter whether we call Dan Vento's feelings pain or suffering? Is this just a semantic issue, a disagreement between two sets of language users that, in the end, doesn't have any adverse consequences?

Yes, it does matter, and yes, it has adverse consequences. It matters because the disagreement reflects a much larger issue: the rigid mindset of the scientific community, which sees the world in a certain way and won't allow for deviation, even from dissenters within its own ranks. Science focuses its spotlight exclusively on the objective world, what can be studied, quantified, and explained. Because it seems resistant to such inquiry, the subjective realm has been traditionally off limits, something that can only be appreciated on much looser terms by the humanities and the "softer" sciences (e.g., psychology).

This mindset informs values, and not just the values of scientists. Because of their position in the intellectual hierarchy, there is a trickle-down effect, which carries over to the practical science of medicine and to the culture at large. In the case of pain, there is only one kind, the real or physical kind that can be objectively verified by observing nociceptor activity or finding lesions on a CAT scan. Other experiences that may feel like pain but cannot be linked to tissue damage are not pain. Much more subjective and less transparently material, they are therefore derivative, less important, and better labeled something else (suffering or anguish).

While psychological pain may be unpleasant, the fact remains that it is "in our heads," not our bodies. As we continue to unfold the logic of the objectivist (and dualistic) paradigm - which has now thoroughly permeated our cultural consciousness - those who suffer without any physical corroboration to show for it inevitably begin to appear suspect. They are either crazy (mentally ill), deceitful (because there is no real pain) or weak (everything is painful to such people). They don't need pain doctors or pain medication, but psychiatrists and priests.

Disregarding for a moment that that all pain is "in the head"- - even Dan Vento's kidney stone pain, which he localized to the right side of his pelvis - the truth is that psychological pain is often more intense and dangerous than the "real thing." For Dan Vento, his bout with kidney stones, among the most painful of all medical conditions, was nothing compared to the pain of grief. Similarly, Lucy Grealy tells us in her memoir, Autobiography of a Face (1995), that she would much rather face the pain of cancer and its treatments than the far worse pain of feeling deformed and lonely (pp. 7, 170, 186). In fact, many such sufferers welcome, even court, physical pain, feeling that it actually alleviates their emotional pain to a degree. And when, unalleviated, the pain becomes too much to bear, some will choose to end it by ending life. Suicide rates are significantly higher in the setting of grief and depression than they are in the setting of physical pain (Schneidman 1998).

In addition to relegating psychological sufferers to second-class status, the prevailing objectivist mindset is also detrimental to another large group of people. Sufferers of chronic pain conditions like migraine, lower back pain, and fibromyalgia find themselves somewhere in limbo between real pain and the derivative, mental kind. On the one hand, their pain seems physical (because it is 
localized to a part of the body), but on the other, it has more in more in common with psychological distress (because there is no detectable injury). For a long time, medicine had no idea what to do with these patients, and so they drifted from doctor to doctor without finding relief. Although their lives have improved with the introduction of pain specialists and pain clinics, chronic pain patients are still often tormented by the insidious logic of the objectivist perspective (see Heshusius 2009, pp. 1-19). Some, in fact, resort to self-mutilation to legitimize their pain in the face of ongoing skepticism from family members and doctors: "You see now," they will say, pointing to their slashed arms, "The pain is not in my head, it's real (see Padfield 2003, pp. 41-43).

I bring up the seriousness of psychological pain and the limbo-like situation of chronic pain conditions because, like the work of a growing number of scientists, it goes against the grain of the prevailing mindset. Perhaps, then, we should change this mindset and broaden our outlook. Instead of privileging one type of pain over another, let's approach them in a more inclusive, democratic spirit, in which all pains are created equal. Or better yet, let's view pain as occurring on a continuum or spectrum that runs from one ideal (pain linked solely to physical injury) to another (pain linked solely to psychological injury).

A spectrum of pain certainly matches our experience more accurately than the conventional paradigm. It accommodates our belief that the feeling of pain can arise from injury to the body as well as injury to the mind. It also accommodates our experience of the considerable overlap between the two varieties, that there is never pure physical or pure psychological pain but always combinations. Those suffering from grief and mental illness often have somatic complaints: Dan Vento felt the loss of his daughter in his gut; William Styron's descent into depression was accompanied by sleeping and breathing problems (Styron 1992, pp. 18, 42-43). At the same time, patients in physical pain inevitably suffer emotionally; cancer patients routinely feel terrified, helpless and lonely (Cherney et al. 1994).

Moreover, the benefits of adopting a broader perspective go beyond validating and valuing our lived experiences. There are practical implications. For science, it would mean more support for the transformative work of researchers like Joseph LeDoux and Antonio Damasio into the subjective realm of feelings and emotions (LeDoux 1996; Damasio 1999). After all, these experiences are as material as the beating of the heart and the DNA molecule, even though at the moment we don't precisely know how to translate neural activity (brain language) into mental states (mind language). So too is psychological pain. Now that we know it shares neurological substrates with physical pain, scientists will no doubt look to extend the work of Eisenberger by finding the "nociceptor pathways" of psychological injury: How are feelings of grief or depression detected and transmitted to the anterior cingular cortex? and How could the signals be modifed? This new mindset might also lead to insight about pathological pain states. Dan Vento's prolonged grief-what psychiatrists classify as complicated grief-has much in common with certain chronic pain states. In both instances, the injury has long past and yet the reverberating pain circuit, no longer serving any biological purpose, continues. Are there similar mechanisms at work here, and might they be manipulated to help Vento escape from his self-destructive rut? 
There would also be changes in the clinical realm, improving the way doctors treat pain. Some patients may require more attention to the body; others, to the mind; the majority, to both. Here too there is room for innovative thinking. Take, for example, the placebo effect in clinical trials, in which a fake pill has been shown to relieve pain on the order of $15-30 \%$ of cases. Most investigators view the phenomenon as a contaminant that must be eliminated to assess the efficacy of the "real" drug. But why not switch frames, as Benedetti (2009) has urged, and focus just as diligently on the reality of the psychological factors that are equally effective, in some cases even more so (pp. 6, 30)? Why not try to harness and enhance these factors to help patients? This same novel way of thinking led DeWall et al. (2010) to administer physical pain medication (acetaminophen) to people suffering from psychological hurt, and not unsurprisingly, it seemed to work.

One of the greatest twentieth-century thinkers, Ludwig Wittgenstein, showed that paying attention to ordinary language can help advance philosophy. Perhaps the same holds true for science. He also showed that clinging dogmatically to a certain picture can lead to conceptual illness (Wittgenstein 1958, Sect. 115). If we can thoroughly break with our unhealthy (and inaccurate) dualistic legacy and truly see that mind and body are inextricably connected, then we must agree with Dan Vento, Joan Didion, and many other sufferers that psychological pain exists and is just as important and worthy of our attention as physical pain. They are two sides of the same coin and should be spoken of and treated as such.

Open Access This article is distributed under the terms of the Creative Commons Attribution Noncommercial License which permits any noncommercial use, distribution, and reproduction in any medium, provided the original author(s) and source are credited.

\section{References}

American Psychiatric Association

1987 Diagnostic and Statistical Manual of Mental Disorders. 3 revrd Edition. Washington, DC: American Psychiatric Association.

Beneddetti, F.

2009 Placebo Effects: Understanding the Mechanisms in Health and Disease. Oxford, UK: Oxford University Press.

Biro, D.

2010 The Language of Pain: Finding Words, Compassion, and Relief. New York: W. W. Norton.

Brand, P., and Y. Yancey

1997 The Gift of Pain. Grand Rapids, MI: Zondervan.

Cassell, E.J.

1991 The Nature of Suffering and the Goals of Medicine. New York: Oxford.

Cherney, N.I., N. Coyle, and K.P. Foley

1994 Suffering in the Advanced Cancer Patient: A Definition and Taxonomy. Journal of Palliative Medicine 10: 51-70.

Damasio, A.

1999 The Feeling of What Happens. New York: Harcourt.

de Mos, M., A.J. de Bruijn, F.J. Huygen, et al.

2007 The Incident of Complex Regional Pain Syndrome: A Population-Based Study. Pain 129: 12-20.

DeWall, N.C., MacDonald, G., Webster, G.D., et al.

2010 Acetaminophin Reduces Social Pain. Psychological Science 21(7): 931-937. 
Didion, J.

2005 The Year of Magical Thinking. New York: Knopf.

Eisenberger, N.I., M.D. Lieberman, and K.D. Williams

2003 Does Rejection Hurt? An fMRI Study of Social Exclusion. Science 302: 209-292.

Grahek, N.

2007 Feeling Pain and Being in Pain. Cambridge, MA: MIT Press.

Grealy, L.

1995 Autobiography of a Face. New York: HarperPerennial.

Gundel, H., M.F. O'Connor, L. Littrell, et al.

2003 Functional Neuroanatomy of Grief: An fMRI Study. American Journal of Psychiatry 160: 19461953.

Heshusius, L.

2009 Inside Chronic Pain: An Intimate and Critical Account. Ithaca, NY: Cornell University Press.

International Association for the Study of Pain 2007 Pain Terminology. Available at: www.iasp-pain.org.

Jamison, K.R.

1996 An Unquiet Mind: A Memoir of Moods and Madness. New York: Vintage.

Katona, C., R. Peveler, C. Dowrick, et al.

2005 Pain Symptoms in Depression: Definition and Clinical Significance. Clinical Medicine 5: 390395 .

LeDoux, L.

1996 The Emotional Brain. New York: Simon \& Shuster.

Melzack, R., and P. Wall

1983 The Challenge of Pain. New York: Basic.

Padfield, D.

2003 Perceptions of Pain. Stockport, UK: Dewi Lewis.

Price, D.D.

2000 Psychological and Neural Mechanisms of the Affective Dimension of Pain. Science 288: 19691972.

Scarry, E.

1985 The Body in Pain: The Making and Unmaking of the World. New York: Oxford.

Schneidman, E.S.

1998 Perspectives on Suicidology: Further Reflections on Suicide and Psychache. Suicide and LifeStyron, W. Threatening Behavior 28: 245-250.

1992 Darkness Visible: A Memoir of Madness. New York: Vintage.

Wittgenstein, L.

1958 Philosophical Investigations. Oxford, UK: Blackwell.

Woolf, C.J., and R.J. Mannion

1998 Neuropathic Pain: Aetiology, Symptoms, Mechanisms, and Management. Lancet 353: 19591964. 